\title{
Spatial and temporal characteristics of soil erosion in a typical karst basin in southwest China and its response to the landscape pattern of rock desertification
}

Jiayong Gao

Guizhou Normal University

Rui Li ( $D$ rlfer@126.com )

Guizhou Normal University https://orcid.org/0000-0003-1097-6683

Maolin He

Guizhou Normal University

Pingping Yang

Guizhou Normal University

Jun Jing

Guizhou Normal University

\section{Research Article}

Keywords: Soil erosion, RUSLE, Landscape pattern, Evolution, Karst basin, Southwest of China

Posted Date: December 1st, 2021

DOl: https://doi.org/10.21203/rs.3.rs-1107552/v1

License: (a) (i) This work is licensed under a Creative Commons Attribution 4.0 International License. Read

Full License 


\section{Abstract}

Soil erosion is a process of migration and redistribution of soil substances in the landscape, which is regulated by topography, vegetation, human activities and their spatial pattern. At the watershed scale, changes in landscape pattern are important factors in determining the degree of soil erosion. Taking Dabang River Basin as the study area, based on the three phases of land use data, remote sensing image data and daily rainfall data from eight stations in the basin in 2010, 2015 and 2020, the rocky desertification factor (D) was introduced into the general soil loss equation RUSLE to calculate the soil erosion in Karst and non-Karst Areas in 2010, 2015 and 2020 respectively. The relationship between landscape pattern and soil erosion was analyzed from two aspects: type level index and landscape level index. The results showed that: 1) From 2010 to 2020, the average soil erosion modulus in The Dabang River Basin decreased first and then increased. The average soil erosion modulus in the non-karst region was about twice that in the karst region, and the average soil erosion modulus in the karst region decreased first and then increased. The mean soil erosion modulus in the non-karst area showed an increasing trend; 2) Under different slope grades, the erosion was mainly slight and mild, and the area of slight erosion was the largest, and the area of very strong and severe erosion increased as the slope increased. the area of strong, very strong and severe erosion increased in the slope zone below $15^{\circ}$, the area of light and moderate erosion decreased, and the area of slight, strong and very strong erosion increased in the slope zone from 15 to $25^{\circ}$, and the area of slight erosion increased in the slope zone above $25^{\circ}$ area increased and light, moderate and strong erosion area decreased in the slope zone above $25^{\circ}$; 3 ) The landscape pattern of the Dadang River Basin changed significantly from 2010 to 2020 . At the landscape level, the number of patches increased and the average patch area decreased. At the type level, the area of paddy field, woodland and shrubland decreases and the area of dry land, grassland, construction land and water body increased, and the dominant land type in the watershed changed from woodland to grassland; 4) The amount of soil erosion was positively correlated with patch type area, landscape percentage, maximum patch index and aggregation index, and positively correlated with edge density; 5) There was a linear relationship between soil erosion and Shannon diversity index (SHDI) and Shannon mean index (SHEI) at landscape level. The results can provide reference for land use planning and soil and water conservation measures.

\section{Introduction}

Soil erosion had become one of the serious environmental and social problems in the world (Higgitt, 1991; Oldeman, 1994), which seriously threatens the health of the ecological environment and restricts the sustainable development of social economy (Kefi et al., 2011). The global land area affected by water erosion was 1.094 billion $\mathrm{hm}^{2}$, of which 7.51 million $\mathrm{hm}^{2}$ was severely eroded (Lal, 2003). In 2019, the area of soil erosion in China reached 1.5761 million $\mathrm{km}^{2}$, of which 1.1347 million $\mathrm{km}^{2}$ was caused by hydraulic erosion, while the area of soil erosion in the rocky desertification area in southwest China was $248,600 \mathrm{~km}^{2}$, accounting for 23.52 percent of the total land area. Once the soil is eroded to form a rocky desertification landscape, it is particularly difficult to repair. The research shows that the soil layer in the rocky desertification area of Southwest China is shallow and the soil formation rate is slow. It takes about 8000 years to form a $1 \mathrm{~cm}$ thick soil layer (Jiang et al., 2014). Affects the occurrence and development of rocky desertification, soil and water loss of rocky desertification development also affect the result of soil and water loss, the 
southwest karst rocky desertification situation day by day serious, the regional ecological security, the people's life and production caused serious influence (Bai et al., 2013; Chen et al., 2011), water loss and soil erosion has become the core issue of the formation and development of rocky desertification of karst area. Is the key to control rock desertification (Xiong et al., 2012). Among the karst areas in southwest China, Guizhou province is the province with the highest concentration, largest area and most serious degree of rock desertification. However, the upper reaches of rivers and river valleys in karst areas are strongly tectonic activities, and rock desertification is relatively serious, such as nanpan River, Beipan River and the upper reaches of Wujiang River basin (Dai et al., 2018). With the development of GIS and RS technology, it is no longer a problem to accurately and rapidly obtain the soil erosion status in the region and determine the erosion-prone areas.At present, a number of estimation models have appeared at home and abroad, mainly including USLE (Wischmeier et al., 1978), RUSLE (Renard and Ferreira, 1993), WEPP (Laboratory UANSE, 1995), CSLE (Liu et al., 2002) and other models. Among which the RUSLE model modified by the United States Department of Agriculture in 1997 based on the Universal soil loss Equation (USLE) has been widely used worldwide. The domestic used of the RUSLE model is mainly concentrated in small watersheds and small areas (Gao et al., 2019; Wang et al., 2009a; Wang et al.,2009b), but the soil erosion in watersheds is a comprehensive process, which is influenced by rainfall, soil, vegetation and other factors, and is also closely related to the landscape pattern of the watershed (Wang et al., 2011).

Landscape pattern and land use are inseparable, different land use methods will lead to changes in the landscape pattern. Rainfall, soil types and topography in the watershed are generally not easy to change significantly, but human activities will significantly change the land use methods and affect the soil erosion of the watershed (Ferreira et al., 2015), such as the conversion of forest land to farmland and grassland will increase the degree of soil erosion (Tarolli et al., 2016), and the conversion of sloping farmland to woodland and grassland can reduce the impact of soil erosion (Yang et al., 2018). Analyzing the evolution of landscape pattern in a watershed has an important impact on the analysis of ecological processes in a watershed. The landscape pattern index is a common tool for landscape pattern analysis. Landscape pattern indexes such as landscape fragmentation, form, diversity, and connectivity are widely used. Describe the relationship between landscape pattern and soil erosion (Shi et al., 2013).

At present, the results of soil loss estimated by RUSLE in karst areas tend to be larger than those observed on the ground, mainly because the impact of bare bedrock on soil erosion in karst areas is not taken into account. Xie (2016) research shows that the RUSLE model with D factor introduced in karst areas has higher accuracy and smaller error than RUSLE model

At present, the results of soil loss in karst areas estimated by RUSLE are often larger than the results of ground observations. The main reason is that the impact of exposed bedrock on soil erosion in karst areas is not considered. Xie (2016) research showed that the area of each erosion level in the RUSLE model that introduces the $D$ factor in karst areas It has higher accuracy and smaller error than the RUSLE model. The Dabang River Basin is a typical karst basin with serious soil erosion. By introducing the rocky desertification factor $(D)$ of the karst region in RUSLE, the soil erosion modulus of the Dabang River Basin was estimated, and the landscape pattern change of Dabang River Basin from 2010 to 2020 and its impact on soil erosion were analyzed. In order to provide the basis for land planning and management and rock desertification control and water and soil conservation planning.

Page $3 / 22$ 


\section{Research Area And Data Sources \\ 1.1 Study area}

Dabang River is a tributary of Beipan River, with geographical locations of $105^{\circ} 15^{\prime} \sim 106^{\circ} 05^{\prime} \mathrm{E}$ and $25^{\circ} 34^{\prime}$ $\sim 26^{\circ} 43^{\prime} \mathrm{N}$ (Figure 1). It originates from Sanzhangshui on the west side of Liuzhi Special Zone and flows through Liuzhi, Zhenning and Guanling before flowing into Beipan River on the south side of Fujiazhai in Guanling County. The main river is $110 \mathrm{~km}$ long, bending coefficient 1.53 , total drop $1169 \mathrm{~m}$, average drop $8.44 \%$. The basin is located in the northeast fold belt on the slope of Yunnan-Guizhou plateau, which is a gentle mountain plain and hilly landform, covering an area of about $2864 \mathrm{~km}^{2}$. The valley has a subtropical warm and moist monsoon climate, and the valley has typical subtropical climate characteristics. Winters are dry and summers are mild; The valley has warm winters and hot summers. The annual average temperature is $19.7^{\circ} \mathrm{C}$, the extreme high temperature is about $33.4^{\circ} \mathrm{C}$, and the extreme low temperature is about $-8.5^{\circ} \mathrm{C}$. The annual average precipitation of the basin was $1279.4 \mathrm{~mm}$, and the distribution was not uniform, mainly concentrated in July to September. The soil types were complex and varied, including yellow soil, red soil, yellow brown soil and paddy soil. In the multi-peak cluster depressions and interriver basins in the basin, the exposed ground layers include lime system, Permian system, Triassic system, Zhuluo System, Paleogene system and Quaternary system. The Triassic system is the main karst area with multiple caves, Wells, springs, funnels, depressions and currents. It is one of the most developed karst landforms in the world, and the karst area in the whole basin accounts for $74.0 \%$ 85.5\%. About 37 percent of the area is soil erosion and 32 percent is rocky desertification.

\subsection{Data source and data processing}

The remote sensing image data in 2010, 2015 and 2020 came from geospatial digital cloud (http://www.gscloud.cn) data, including Landsat5 TM data in 2010 and Landsat8 data in 2015 and 2020; DEM $(30 \mathrm{~m})$, land use data and soil data were obtained from the Resource and Environmental Science and Data Center of Chinese Academy of Sciences (https://www.resdc.cn), and rainfall data were provided by Guizhou Hydrology and Water Resources Bureau, including daily rainfall data of 8 stations, such as Anxi, Dabang, Gaoche, Guijiahu, Huangguoshu, Pogong, Shaying and Yongning. Remote sensing image data were preprocessed to extract vegetation coverage and rock exposure rate.

\section{Research Methods}

\subsection{Calculation of watershed soil erosion modulus}

The RUSLE model is revised on the basis of the universal soil loss model USLE, which is widely used in the world. It is closely combined with GIS and RS. Based on rainfall erosivity, soil erodibility, topography, vegetation management and protection measures, the annual soil erosion modulus is estimated by factor calculation, and the expression is as follows:

$A=R \times K \times L S \times C \times P(1)$ 
Where $A$ is the annual soil erosion modulus $\left(\mathrm{t} \cdot \mathrm{ha}^{-1} \cdot \mathrm{a}^{-1}\right), R$ is the rainfall erosivity factor $\left(\mathrm{MJ} \cdot \mathrm{mm} \cdot \mathrm{hm}^{-1} \cdot \mathrm{h}^{-1} \cdot \mathrm{a}^{-1}\right)$, and $K$ is the soil available Corrosion factor $\left(\mathrm{t} \cdot \mathrm{hm}^{2} \cdot \mathrm{h} \cdot \mathrm{MJ}^{-1} \cdot \mathrm{mm}^{-1} \cdot \mathrm{hm}{ }^{-2}\right), L S$ is the slope length and slope factor, $C$ is the vegetation cover factor, and $P$ is the water and soil conservation measure factor.

The RUSLE model failed to consider the impact of rocky desertification in karst areas, resulting in the calculated soil erosion modulus often greater than the actual soil erosion modulus (Li and Pan, 2021). In karst areas, the increase of bedrock bare rate will lead to the decrease of soil erosion (Cerdà, 2010; Wang et al., 2012). Therefore, based on previous practices (Xie, 2016), this study introduced the Factor of Rocky Desertification (d-factor) to modify the RUSLE model:

$$
A=R \times K \times L S \times C \times P \times(1-D)
$$

2

Where $A$ is the annual soil erosion modulus $\left(\mathrm{t} \cdot \mathrm{ha}^{-1} \cdot \mathrm{a}^{-1}\right), R$ is the Rainfall Erosivity Factor $\left(\mathrm{MJ} \cdot \mathrm{mm} \cdot \mathrm{hm}^{-1} \cdot \mathrm{h}^{-1} \cdot \mathrm{a}^{-1}\right), K$ is the soil erodibility factor $\left(\mathrm{t} \cdot \mathrm{hm}{ }^{2} \cdot \mathrm{h} \cdot \mathrm{MJ}^{-1} \cdot \mathrm{mm}^{-1} \cdot \mathrm{hm}^{-2}\right), L S$ is the slope length and slope factor, $C$ is the vegetation coverage factor, $P$ is the soil and water conservation measure factor, and $D$ is the rocky desertification factor.

\subsubsection{Rainfall erosivity factor $(R)$}

Rainfall is the direct driving force of soil erosion and the erosivity of rainfall is the index reflecting the ability of soil stripping and transport by rainfall. Based on the daily rainfall data of eight rainfall stations in anxi, Dabang, Gaoche, Guijiahu, Huangguoshu, Pogong, Shaying and Yongning in the research area in 2010, 2015 and 2020 , this paper compared various methods and selected the modified daily rainfall model established by Shi et al. (2006). The specific formula is as follows:

$$
R_{j}=0.429\left\{1+0.328 \sin \left[\frac{\Pi}{12}(j-1)\right]\right\} \sum_{k=1}^{n} P_{k}^{1.47}
$$

3

Where $R_{j}$ is the rainfall erosivity of month $j\left(\mathrm{MJ} \cdot \mathrm{mm} \cdot \mathrm{hm}^{-2} \cdot \mathrm{h}^{-1} \cdot \mathrm{a}^{-1}\right), P_{K}$ is the rainfall of month $K(\mathrm{~mm})$, and the model daily erosive rainfall standard is $12 \mathrm{~mm}$. The annual rainfall erosivity of each rainfall station is calculated by using the above formula, and the inverse distance weight interpolation is carried out in ArcGIS to obtain the spatial grid data of rainfall erosivity with a spatial resolution of $30 \mathrm{~m}$ in Dabang River Basin in 2010, 2015 and 2020.

\subsubsection{Soil erodibility factor $(K)$}

Soil erodibility, which is related to soil texture, soil structure, compactness and organic matter content, is an internal factor of soil, an index reflecting soil sensitivity to erosion, and an important parameter for soil erosion prediction and water conservation benefit evaluation. Based on soil organic carbon data and soil 
particle composition data, $\mathrm{K}$ factor was calculated by using the Evaluation-Productivity Impact Calculator (EPIC) model (Sharpley and Williams, 1990). The specific formula is as follows:

$$
\begin{gathered}
K=0.2+0.3 \exp [-0.0256 S A N \cdot(1-S I L / 100)] \cdot\left(\frac{S I L}{C L A+S I L}\right)^{0.3} \\
\cdot\left[1.0-\frac{0.25 C}{C+\exp (3.72-2.95 C)}\right] \cdot\left[1.0-\frac{0.7 S N_{1}}{S N_{1}+\exp \left(-5.51+22.9 S N_{1}\right)}\right]
\end{gathered}
$$

\section{4}

Where $S A N$ is sand content $(0.05 \sim 2.00 \mathrm{~mm}), \%$; $S / L$ is the powder content $(0.002 \sim 0.05 \mathrm{~mm}), \%$; $C L A$ is clay content $(<0.002 \mathrm{~mm}), \% ; S N_{1}=1-S A N / 100 ; C$ is organic carbon content, \%; The obtained results are multiplied by 0.1317 and converted into the international system, with the unit of $t \cdot \mathrm{hm}^{2} \cdot \mathrm{h} \cdot \mathrm{MJ}^{-1} \cdot \mathrm{mm}^{-1} \cdot \mathrm{hm}^{-2}$. The calculated $K$ values are assigned in the soil type map and converted into a $K$ value map with a spatial resolution of $30 \mathrm{~m}$.

\subsubsection{Topographic factor ( $L S)$}

Topography factor (LS) mainly refers to slope length factor $L$ and slope factor $S$, which are indicators to measure the impact of topography on soil erosion. The larger the slope is, the larger the runoff is, and the stronger the erosion ability of the slope is. The longer the slope, the greater the runoff and the stronger the erosion. The study area in this paper is a typical small karst watershed, so DEM data with a spatial resolution of $30 \mathrm{~m}$ is used to extract slope length and gradient.

The $S$ factor is calculated as follows (McCool et al., 1987; Liu et al., 2000):

$$
S= \begin{cases}10.8 \sin \theta+0.03 & \theta<5^{\circ} \\ 16.8 \sin \theta-0.05 & 5^{\circ} \leq \theta<10^{\circ} \\ 21.9 \sin \theta-0.96 & \theta \geq 10^{\circ}\end{cases}
$$

The $L$ factor is calculated as follows (Zhang et al., 2013):

$$
L=(\lambda / 22.13)^{n}
$$

6

$$
n=m /(1+m)
$$

7

$$
m=(\sin \theta / 0.0896) /\left[3.0(\sin \theta)^{0.8}+0.56\right]
$$

8

Where, $L$ is slope length factor, $S$ is slope factor, $\theta$ is slope value extracted from DEM data, $n$ and $m$ are slope index and rill erosion to surface erosion ratio respectively. 


\subsubsection{Vegetation cover management factor $(C)$, Soil and water conservation measure factor $(P)$ and rocky desertification factor $(D)$}

(1) Vegetation cover management factor $(C)$ : refers to the ratio of soil loss to the same bare land loss under certain surface cover and management measures, generally between $0 \sim 1$, reflecting the impact of vegetation cover management measures on soil erosion. In this paper, using the corresponding relationship between $f$ (Fractional Vegetation coverage) and $C$ value obtained by Cai et al. (2000), $\mathrm{f}$ in the study area is calculated according to the pixel dichotomy (Gillies et al., 1997), and then c value is obtained. The specific formula is as follows:

$$
\begin{gathered}
C=\left\{\begin{array}{cl}
1 & 0 \leq f<10 \% \\
0.6508-0.3436 \times 1 \mathrm{~g} f & 10 \% \leq f<78.3 \% \\
0 & f \geq 78.3 \%
\end{array}\right. \\
f=\left\{\begin{array}{cl}
N_{\text {NDII }}<N_{\text {soi }} \\
0 & N_{\text {NDII }}>N_{\text {veg }} \\
1 & N_{\text {soi }} \leq N_{\text {NDII }} \leq N_{\text {veg }} \\
\left(N_{\text {NDIT }}-N_{\text {soi }}\right) /\left(N_{\text {veg }}-N_{\text {soil }}\right) &
\end{array}\right. \\
N D V I=\frac{T M 4-T M 3}{T M 4+T M 3}
\end{gathered}
$$

Where $N D V I$ is the normalized vegetation index, TM4 is near-infrared light, and the wavelength is $0.76 \sim 0.90$ $\mu \mathrm{m}$. TM3 is red light with a wavelength of $0.63 \sim 0.69 \mu \mathrm{m}$. According to the pixel dichotomy, $2 \%$ of the corresponding pixel values are $N_{\text {soil }}, 98 \%$ of the corresponding pixel values are $N_{v e g}, f$ is the vegetation coverage, and $C$ is the vegetation coverage management factor.

(2) Water and soil conservation measure factor $(P)$ : refers to the ratio of slope erosion after water and soil conservation measures are applied to cultivated land under the same other conditions, reflecting the inhibitory effect of water and soil conservation measures on soil erosion, ranging from 0 to 1 . Referring to the previous research results (Gao et al., 2019; Feng et al.,2016), the value of paddy field is 0.15; The value of dry land is 0.4; Woodland, open woodland, shrub and grassland are assigned as 1 ; Water body, construction land, bare land and bare rock land are assigned as 0 (Table 1).

Table 1

$P$ value of water and soil conservation measures

\begin{tabular}{|lllllllllll|}
\hline $\begin{array}{l}\text { Land } \\
\text { use }\end{array}$ & $\begin{array}{l}\text { Paddy } \\
\text { land }\end{array}$ & $\begin{array}{l}\text { Dry } \\
\text { land }\end{array}$ & Forest & $\begin{array}{l}\text { Open } \\
\text { forest }\end{array}$ & Shrub & Grassland & $\begin{array}{l}\text { Water } \\
\text { body }\end{array}$ & $\begin{array}{l}\text { Construction } \\
\text { land }\end{array}$ & $\begin{array}{l}\text { Bare } \\
\text { land }\end{array}$ & $\begin{array}{l}\text { Bare } \\
\text { rock }\end{array}$ \\
\hline$P$ & 0.15 & 0.4 & 1 & 1 & 1 & 1 & 0 & 0 & 1 & 0 \\
\hline
\end{tabular}

(3) Rocky desertification factor $(D)$ : refers to the reduction of soil erosion and water and soil loss in rocky desertification areas due to the inhibition of soil erodibility and runoff by a large number of exposed rocks. With reference to previous research results Xie (2016), factor $D$ is expressed by rock exposure rate, dimensionless. 


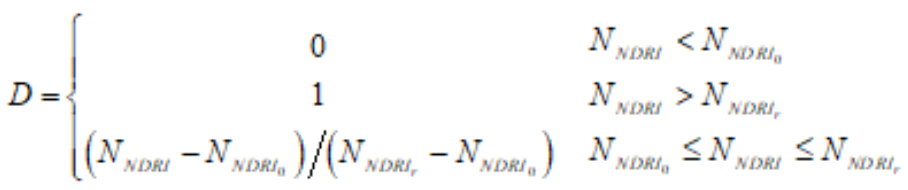

$$
\begin{aligned}
& N D R I=\frac{T M 7-T M 4}{T M 7+T M 4}
\end{aligned}
$$

Where NDR/ is normalized rock index, TM7 is short wave infrared, and the wavelength is 2.08 2.35 $\mu \mathrm{m}$. TM4 is near infrared with a wavelength of $0.76 \sim 0.9 \mu \mathrm{m}$. According to the pixel dichotomy, $2 \%$ of the corresponding pixel value is $N D R I_{0}, 98 \%$ of the corresponding pixel value is $N D R I_{n}$ and $D$ is the rock exposure rate.

\subsection{Selection and calculation of landscape index}

The land use was divided into paddy field, dry land, forest land, shrubland, grassland, construction land, water body, bare land and bare rock land. In order to reflect the impact of landscape pattern on soil erosion, landscape level index and type level index were selected to analyze the change of landscape pattern in Dapang River basin from 2010 to 2020. At the landscape level, seven indexes were selected, including patch number (NP), average patch area (AREA_MN), average shape index (SHAPE_MN), average adjacency index (CONTIG_MN), Shannon diversity index (SHDI), average fractal dimension index (FRAC_MN) and Shannon evenness index (SHEI). At the type level, seven indexes were selected, including patch type area (CA), landscape percentage (PLAND), patch density (PD), maximum patch index (LPI), patch edge density (ED), landscape shape index (LSI) and aggregation index (Al) were selected (Gao et al., 2021). All landscape indexes are calculated by the landscape structure quantification software FRAGSTATS. See reference (Wu, 2007) and FRAGSTATS manual for the ecological significance and calculation formula of each landscape index.

\subsection{Correlation analysis and regression analysis}

In order to explore the response of soil erosion to rocky desertification landscape pattern, RStudio software was used to analyze the correlation between soil erosion amount and type level index of different regions in The Dabang River Basin from 2010 to 2020. With the annual average soil erosion amount as the dependent variable and landscape level index as the independent variable, stepwise regression analysis was conducted with SPSS software to explore the impact of landscape pattern on soil erosion at the watershed scale.

\section{Results And Analysis}

\subsection{Spatial and temporal variation characteristics of soil in Dabang River Basin}

(1) Changes of soil erosion in Dabang River Basin from 2010 to 2020 
The soil erosion modulus of non-karst areas in the basin is calculated by formula (1), and that of karst areas is calculated by formula (2). Dabang River Basin is a typical karst basin, and the soil erosion intensity is divided into six grades according to the standard for classification and classification of soil erosion (SL1902007) (Table 2). From 2010 to 2020, the average soil erosion modulus of Dabang River Basin decreased first and then increased. The average soil erosion modulus in 2010 was $25.18 \mathrm{t} \cdot \mathrm{ha}^{-1} \cdot \mathrm{a}^{-1}$, that in 2015 was 24.20 $\mathrm{t} \cdot \mathrm{ha} \mathrm{a}^{-1} \cdot \mathrm{a}^{-1}$, and that in 2020 was $26.75 \mathrm{t} \cdot \mathrm{ha}^{-1} \cdot \mathrm{a}^{-1}$. In 2010,2015 and 2020 , the basin was dominated by micro erosion and mild erosion, accounting for about $71 \%$ of the total area, of which the micro erosion area increased by $411.94 \mathrm{~km}^{2}$ by 2020, the mild erosion area showed a decreasing trend, and decreased by 335.59 $\mathrm{km}^{2}$ by 2020 , about $43.41 \%$; The moderately eroded area showed a decreasing trend, which decreased by $126.81 \mathrm{~km}^{2}$ by 2020 , about $33.61 \%$; The strongly eroded area increased first and then decreased. From 2015 to 2020 , it changed greatly, decreasing by $39.72 \mathrm{~km}^{2}$, about $18.24 \%$; The extremely strong erosion area showed an increasing trend. From 2010 to 2015 , it changed greatly, increasing by $26.47 \mathrm{~km}^{2}$, about $15.16 \%$; the area of severe erosion first decreased and then increased. It increased by $60.85 \mathrm{~km}^{2}$ in 2020 compared with 2015 , nearly doubling.

Table 2

Area of each erosion grade from 2010 to 2020

\begin{tabular}{|lllllll|}
\hline Soil erosion intensity & $\mathbf{2 0 1 0}$ & Ratio & $\mathbf{2 0 1 5}$ & Ratio & $\mathbf{2 0 2 0}$ & Ratio \\
\hline Slight & 1279.98 & $44.36 \%$ & 1455.75 & $50.45 \%$ & 1691.92 & $58.64 \%$ \\
\hline Mild & 773.04 & $26.79 \%$ & 608.55 & $21.09 \%$ & 437.46 & $15.16 \%$ \\
\hline Moderate & 377.33 & $13.08 \%$ & 337.54 & $11.70 \%$ & 250.52 & $8.68 \%$ \\
\hline Strong & 209.83 & $7.27 \%$ & 217.70 & $7.54 \%$ & 177.99 & $6.17 \%$ \\
\hline Pole strong & 174.63 & $6.05 \%$ & 201.10 & $6.97 \%$ & 201.76 & $6.99 \%$ \\
Violent & 70.50 & $2.44 \%$ & 64.99 & $2.25 \%$ & 125.85 & $4.36 \%$ \\
\hline
\end{tabular}

(2) Soil erosion in Karst and Non-karst areas in the basin

As can be seen from Table 3, the average soil erosion modulus of the karst region in the basin fluctuated firstly and then increased during 2010-2020. The average soil erosion modulus in 2015 was the lowest (20.82 $\left.\mathrm{t} \cdot \mathrm{ha} \mathrm{a}^{-1} \cdot \mathrm{a}^{-1}\right)$, and the average soil erosion modulus in 2020 was the largest $\left(23.45 \mathrm{t} \cdot \mathrm{ha} \mathrm{a}^{-1} \cdot \mathrm{a}^{-1}\right)$. The average soil erosion modulus in non-karst areas showed an increasing trend. The average soil erosion modulus in 2020 was the largest, which was $46.37 \mathrm{t} \cdot \mathrm{ha}^{-1} \cdot \mathrm{a}^{-1}$, an increase of $4.79 \%$ compared with 2015 . The maximum soil erosion modulus in non-karst areas showed an increasing trend, and it changed greatly from 10 to 15 years, with an increase of $252.43 \mathrm{t} \cdot \mathrm{ha}^{-1} \cdot \mathrm{a}^{-1}$, and an increase of $36.06 \%$ compared with 10 years. In the karst region, the maximum soil erosion modulus decreased firstly and then increased, but in general the maximum soil erosion modulus decreased. 
In general, the average soil erosion modulus of the karst region was lower than that of the non-karst region, and the average soil erosion modulus of the non-karst region was about twice that of the non-karst region. The maximum soil erosion modulus of the karst region was generally larger than that of the non-karst region.

Table 3 Soil erosion in Karst and non-karst areas in the basin from 2010 to 2020

\begin{tabular}{|c|c|c|c|c|c|c|}
\hline & & & & & & Unit: $\mathrm{t} \cdot \mathrm{ha}^{-1} \cdot \mathrm{a}^{-1}$ \\
\hline Area & Year & Min & Max & Rate of change & Average value & Rate of change \\
\hline \multirow{3}{*}{ Karst area } & 2010 & 0 & 1017.14 & - & 22.15 & - \\
\hline & 2015 & 0 & 821.29 & $-19.25 \%$ & 20.82 & $-6.00 \%$ \\
\hline & 2020 & 0 & 999.85 & $21.74 \%$ & 23.45 & $12.63 \%$ \\
\hline \multirow{2}{*}{ Non-karst } & 2010 & 0 & 699.98 & - & 43.19 & - \\
\hline & 2015 & 0 & 952.41 & $36.06 \%$ & 44.25 & $2.45 \%$ \\
\hline area & 2020 & 0 & 955.36 & $0.31 \%$ & 46.37 & $4.79 \%$ \\
\hline
\end{tabular}

(3) Changes of soil erosion intensity under different slope conditions

According to the slope, the basin is divided into 6 levels: $0 \sim 5^{\circ}, 5 \sim 8^{\circ}, 8 \sim 15^{\circ}, 15 \sim 25^{\circ}, 25 \sim 35^{\circ}$ and $>35^{\circ}$. As can be seen from Figure 2, the terrain of the Dabang River Basin is broken and the mountains are high and steep, and the area with the slope of $15 \sim 25^{\circ}$ and $8 \sim 15^{\circ}$ accounts for about $55 \%$ of the total area of the basin. From 2010 to 2020 , the variation trend of soil erosion intensity was basically consistent with slope, which was mainly slight erosion and mild erosion under different slope grades, and the area of slight erosion accounted for the largest proportion. With the increase of slope, the area of extremely intense erosion and severe erosion gradually increased.

From 2010 to 2020, the area of slight erosion decreased and the area of slight erosion increased at 0-5 ${ }^{\circ}$ level. At the level of $5^{\circ} \sim 8^{\circ}$, the area of slight and mild erosion decreased, while the area of moderate, intense and extremely intense erosion increased. At the level of $8^{\circ} \sim 15^{\circ}$, the area of slight erosion increased, the area of mild erosion decreased, and the area of moderate erosion increased first and then decreased, which was higher than that in 2010 . At the level of $15^{\circ} \sim 25^{\circ}$, the area of slight erosion, extremely intense erosion and intense erosion increased, while the area of mild erosion and moderate erosion decreased, and the area of intense erosion increased first and then decreased. At $25^{\circ} \sim 35^{\circ}$ level, slight erosion area increased, light, moderate and intense erosion area decreased, extremely intense erosion area first increased and then decreased, and severe erosion area first decreased and then increased. $>35^{\circ}$, the area of slight erosion increased, while the area of mild, moderate, intense and extremely intense erosion decreased, and the area of severe erosion decreased first and then increased.

\subsection{Analysis of the changes in the landscape of the river basin 3.2.1 Analysis of the landscape index}

According to the watershed landscape level index of the basin (Table 4), the number of patches (NP) showed an increasing trend from 2010 to 2020, with an increase of $10.69 \%$ in ten years. The larger the NP value was, 
the higher the degree of landscape fragmentation in the basin was. The average patch area (AREA_MN) showed a decreasing trend, decreased by $9.65 \%$, and the index showed that the degree of landscape fragmentation in the basin became larger. The average shape index (SHAPE_MN) and average fractal dimension index (FRAC_MN) decreased slightly, indicating that the shape of landscape patches in Dabang River Basin tended to be stable and was subject to more human disturbance. The average adjacency index (CONTIG_MN) decreased slightly, indicating that the connections between landscape patches and other patches in the basin were reduced and the landscape was scattered. Shannon diversity index (SHDI) reflected landscape heterogeneity and was sensitive to the unbalanced distribution of patch types in the landscape. The SHDI value showed an increasing trend from 2010 to 2020, indicating that land use in the watershed was becoming richer and more fragmented, and the information content of instability was increasing. Shannon evenness index (SHEI) firstly decreased and then increased, indicating that the distribution evenness of patches in landscape was improved and diversity was gradually increased from 2010 to 2020 .

Table 4

landscape level index of Dabang River from 2010 to 2020

\begin{tabular}{|llllllll|}
\hline Year & NP & AREA_MN & SHAPE_MN & FRAC_MN & CONTIG_MN & SHDI & SHEI \\
\hline 2010 & 1909 & 151.397 & 2.746 & 1.130 & 0.794 & 1.539 & 0.740 \\
\hline 2015 & 2004 & 144.219 & 2.651 & 1.125 & 0.786 & 1.545 & 0.703 \\
\hline 2020 & 2113 & 136.780 & 2.566 & 1.121 & 0.764 & 1.578 & 0.718 \\
\hline $\begin{array}{l}\text { Notes: NP: Number of patches, AREA_MN: Average patch area, SHAPE_MN: average shape index, } \\
\text { FRAC_MN: average fractal dimension index, CONTIG_MN: Average adjacency index; SHDI: Shannon } \\
\text { diversity index; SHEl: Shannon evenness index }\end{array}$ \\
\hline
\end{tabular}

\subsubsection{Type level index analysis}

Dabang River type level index from 2010 to 2020 is shown in Figure 3. According to patch type area (CA), the area of paddy field, woodland and shrub decreased, while the area of other land types increased, among which the area of dry land increased the most, followed by grassland, and the area of construction land and water body increased less. The percentage of landscape (PLAND) and maximum patch index (LPI) reflect patch dominance, with a shift from woodland to grassland in the watershed, followed by a significant increase in upland PLAND and LPI, consistent with the change in CA. Patch density (PD) represents the degree of landscape fragmentation, and the larger the value is, the higher the degree of landscape fragmentation is. The PD value of dryland in 10 and 15 years is the largest, and that of paddy field in 20 years is the largest, indicating the higher degree of landscape fragmentation of cultivated land on the whole. The marginal density (ED) of the species varied little. Landscape shape Index (LSI) reflects the complexity of the overall landscape. The closer THE LSI is to 1, the simpler the overall landscape shape is, and the larger the LSI is, the more complex the overall landscape shape is. The LSI value of paddy field and dry land is significantly higher than that of other types, indicating that the two types of land have a high degree of edge 
fragmentation and landscape fragmentation. The aggregation degree index (Al) changed little on the whole, indicating that the landscape distribution of the basin as a whole was uniform and tended to be stable.

\subsection{Impact of watershed landscape pattern changed on soil erosion}

(1) Correlation analysis between type level index and soil erosion in different regions

It can be seen from Fig. 4 that the soil erosion amount of various types in Dabang River Basin was highly significantly positively correlated with the patch type area (CA) $(P<0.01)$, that is, the larger the patch type area, the greater the soil erosion amount. Patch type area refers to the total area of a patch type, and its value is of great significance to the species richness, quantity and food chain of this type of patch as an aggregation place. There was a very significant positive correlation between soil erosion and landscape percentage (PLAND). Landscape percentage refers to the percentage of the total area of a patch type to the landscape area of the whole watershed, which is an important basis to determine the dominant patch type in the watershed landscape. There was a very significant positive correlation between soil erosion and the maximum patch index $(\mathrm{LPI})$, that is, the greater the value of the maximum patch index, the greater the average soil erosion of the land. LPI refers to the proportion of the area of the largest patch in a patch type in the watershed landscape area, which is helpful to determine the dominant land types in the landscape. There is a very significant positive correlation between soil erosion and aggregation index (Al). At the type level, landscape aggregation degree indicates the non-random probability or aggregation degree of different patch types in the landscape. The higher the Al value, the greater the patch aggregation degree. There was a significant positive correlation between edge density (ED) and soil erosion $(P<0.05)$. Edge density refers to the edge length between patches of heterogeneous landscape elements per unit area. The greater the edge density, the greater the amount of soil erosion.

(2) Multiple linear regression model fitting between landscape level index and soil erosion

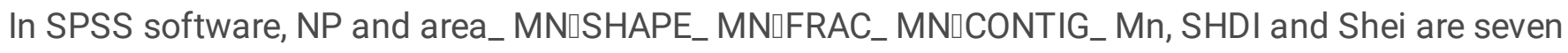
landscape pattern indexes as independent variables and soil erosion modulus as dependent variables. Through stepwise regression analysis, the model of soil erosion modulus on landscape level index is finally obtained as follows:

$A=61.119 \times S H D I+37.732 \times S H E I-96.794$

Where $A$ is the soil erosion modulus $\left(\mathrm{t} \cdot \mathrm{hm}^{-2} \cdot \mathrm{a}^{-1}\right), S H D /$ is the Shannon diversity index, and $S H E /$ is the Shannon evenness index.

\section{Discussion}

\subsection{Impact of landscape pattern on soil erosion}


Landscape pattern is closely related to land use and is mainly affected by human activities. From 2010 to 2020, the landscape pattern of Dabang river basin changed significantly, in which the area of paddy field, forest land and shrub decreased, and the area of dry land, grassland, construction land and water body increased. In recent years, the acceleration of urbanization in Dabang River Basin has led to the rapid increase of a large number of urban and rural construction land and transportation construction land, which is the main reason for the increase of construction land in Dabang River Basin. The change of land use mode directly affects the P factor in RUSLE model. From 2010 to 2020, a large number of paddy fields were converted to drylands, and the $\mathrm{P}$ factor changed, resulting in the change of soil erosion modulus. On the watershed scale, under the direct influence of human disturbance, the landscape fragmentation, Shannon diversity index and soil erosion increase (Shi et al., 2013). From the type level, grassland has evolved into the dominant land type in the basin in 2020. The stronger the advantage of a single land type, the stronger the soil erosion (Shi et al., 2013; Gao et al., 2021). Soil erosion is a spatial process, and the edge density of patches has a significant positive correlation with the amount of soil erosion. The implementation of the project of returning farmland to forest and grassland has increased the vegetation coverage in the basin, the area proportion of grassland in the basin has been increasing, and the larger edge density of grassland patches has increased the sediment transport at the edge of patches (Wei et al., 2010), so the amount of soil erosion is greater.

\subsection{Impact of rocky desertification on soil erosion}

After introducing $D$ factor by linear correction in RUSLE model, it is found that the average soil erosion modulus of karst area in the basin from 2010 to 2020 is much smaller than that of non-karst area (Wei et al., 2011; Li et al., 2019a), and the accuracy and accuracy of soil erosion estimation in the basin are significantly improved (Xie, 2016). The relationship between rock exposure and soil erosion is complex, and there are linear (A Cerdà, 2010), exponential (Martínez-Zavala L, 2008), quadratic function (Han et al., 2019), etc. However, at present, there are few studies on the impact of rocky desertification on soil erosion (Ma and Zhang, 2018), and most of them are based on indoor simulation tests and lack of field positioning observation tests. Therefore, a broad consensus has not been formed on which relationship is used to modify the soil loss model. Therefore, the linear correction method may have some limitations. Referring to the establishment of the general soil loss equation in the United States, the field positioning observation is of great significance for the study of factor $D$. It is very necessary to establish the rocky desertification community by "transplanting" rocks. According to different rock exposure rates and based on long-term positioning observation, it is necessary to explore the impact of rocky desertification on Soil and water loss, and then introduce factor $D$ to modify RUSLE model. Rocky desertification has many effects on soil erosion: on the one hand, a large number of exposed rocks reduce the area of soil erosion; On the other hand, exposed rocks can increase the surface runoff inflow and infiltration rate by inhibiting soil erodibility and runoff generation, so as to greatly reduce soil erosion (A Cerdà, 2010; Li et al., 2019). Since the implementation of the national comprehensive rocky desertification control project in Guizhou Province in 2011, the effect of rocky desertification control in Dabang River Basin has been remarkable, the areas without rocky desertification and mild rocky desertification have increased significantly, the areas with severe rocky desertification and extremely severe rocky desertification have decreased, the rock exposure rate has decreased, and the grassland has evolved 
into the dominant land type of the basin, accounting for $33.14 \%$ of the basin area, and the forest land accounts for $27.99 \%$ of the basin area, The increase of vegetation coverage leads to the decrease of $C$ factor and $D$ factor in RUSLE model. Due to the decrease of $C$ and $D$ factors, the average soil erosion modulus of karst area in the basin decreased from 2010 to 2015, but the rainfall erosivity increased in the same period, indicating that $C$ and $D$ factors play a leading role in soil erosion; From 2015 to 2020, $D$ factor decreased, but soil erosion modulus increased, which may be related to the significant increase of $R$ factor during this period.

The research shows that the average soil erosion modulus in the karst area of Dabang river basin is less than that in the non-karst area of the basin, but the soil layer around the exposed rocks is shallow and loose, which is very prone to water and soil loss, and even some areas with serious rocky desertification have reached the point of no soil erosion. Therefore, we should pay more attention to the prevention and control of water and soil loss in the rocky desertification area.

\subsection{Impact of other factors on soil erosion in the basin}

The spatial and temporal variation of soil erosion intensity in Dabang river basin is related to rainfall, topography and human activities. Spatially, with the increase of slope, the area of extremely strong and severe erosion gradually increases, because the slope restricts the erosivity of rainfall runoff and the stability of soil materials. The larger the slope, the faster the water flow generated during rainfall, the stronger the water scouring and carrying capacity, and it is easier to cause water and soil loss. In terms of time, the area of extremely strong and severe erosion below $25^{\circ}$ in Dabang River Basin increases, on the one hand, because the rainfall erosivity of the basin increases from 2010 to 2020, on the other hand, because most of the slope zones below $25^{\circ}$ are slope cultivated land, which is the concentrated area of human farming activities and the main source of regional water and soil loss (Li et al., 2019b), Frequent agricultural activities destroyed the stable structure of soil, and the harvest of crops significantly reduced the vegetation coverage; The slight erosion area in the slope zone above $25^{\circ}$ increases and the mild, moderate and strong erosion area decreases, because the area above $25^{\circ}$ is mainly grassland and forest land, with weak human activities. The forest land and grassland consolidate the soil through their developed roots, improve the soil texture, and the vegetation canopy has interception effect, reducing the splash erosion of rain on the soil, thus reducing soil erosion (Xiong et al., 2019).

\section{Conclusion}

Taking Dabang River Basin as the research object, this paper estimates Dabang River Basin by introducing rocky desertification factor into RUSLE model, and analyzes the relationship between landscape pattern change and soil erosion by using landscape pattern index. The following conclusions are obtained:

1) From 2010 to 2020, the average soil erosion modulus of Dabang River Basin decreased first and then increased, mainly micro and mild erosion, the micro erosion area increased, the moderate erosion area decreased, and the extremely strong erosion and severe erosion area increased; The average soil erosion modulus of non-karst areas in the basin is about twice that of karst areas. The average soil erosion modulus 
of karst areas decreases first and then increases, and the average soil erosion modulus of non-karst areas increases;

2) Under different slope grades, micro erosion and mild erosion are the main types, and the area of micro erosion accounts for the largest proportion. With the increase of slope, the area of extremely intense and severe erosion increases, the area of intense, extremely intense and severe erosion increases in the slope zone below $15^{\circ}$, the area of mild and moderate erosion decreases in the slope zone of $15 \sim 25^{\circ}$, and the area of micro, intense and extremely intense erosion increases, the area of slight erosion increases and the area of mild, moderate and strong erosion decreases in the slope zone above $25^{\circ}$;

3) The landscape pattern of Dabang River Basin has changed significantly from 2010 to 2020. At the landscape level, the number of patches increased, the average patch area decreased, the degree of landscape fragmentation increased, the patch shape was simple, the uniformity of patch distribution improved, and the landscape diversity increased; At the type level, the area of paddy field, forest land and shrub forest decreases, the area of dry land, grassland, construction land and water body increases, the dominant land type in the basin changes from forest land to grassland, the edge of cultivated land is highly fragmented, the degree of fragmentation is the largest, and the landscape distribution of the basin as a whole is uniform and tends to be stable;

4) The amount of soil erosion was positively correlated with patch type area, landscape percentage, maximum patch index and aggregation index, and positively correlated with edge density;

5) At the landscape level, the amount of soil erosion has a linear relationship with Shannon diversity index $(S H D I)$ and Shannon evenness index (SHEI).

\section{Declarations}

\section{Declaration of Competing Interest}

The authors declare that they have no known competing financial interests or personal relationships that could have appeared to influence the work reported in this paper.

\section{Acknowledgements}

Thank you very much for the rainfall data provided by Guizhou water resources bureau and Dr. Shu's guidance. This work was supported by National Natural Science Foundation of China (NO. 31760243, 32060372); the Guizhou Science and Technology Department (Qiankehe Zhicheng [2021] Yiban462).

\section{References}

A Cerdà (2010) Effects of rock fragment cover on soil infiltration, interrill runoff and erosion. European Journal of Soil Science 52(1):59-68.

Bai X Y, Wang S J, Xiong K N (2013) Assessing spatial-temporal evolution processes of karst rocky desertification land: indications for restoration strategies. Land Degradation \& Development 24(1):47-56 
Cai C F, Ding S W, Shi Z H, Huang L (2000) Study of applying USLE and geographical information system IDRISI to predict soil erosion in small watershed. Journal of Soil and Water Conservation, (2):19-24. (in Chinese)

Chen H, Liu J, Wang K, Wei Z (2011) Spatial distribution of rock fragments on steep hillslopes in karst region of northwest Guangxi, China. Catena 84(1-2):21-28.

Dai Q H, Yan Y J (2018) Research progress of karst rocky desertification and soil erosion in southwest China. Journal of Soil and Water Conservation 32(2):1-10. (in Chinese)

Feng T, Chen H S, Polyakov V O, Wang K L, Zhang X B, Zhang W (2016) Soil erosion rates in two karst peakcluster depression basins of northwest Guangxi, China: comparison of the RUSLE model with ${ }^{137} \mathrm{Cs}$ measurements. Geomorphology 253:217-224.

Ferreira V, Panagopoulos T, Cakula A, R Andrade, A Arvela (2015) Predicting Soil Erosion After Land Use Changes for Irrigating Agriculture in a Large Reservoir of Southern Portugal. Agriculture \& Agricultural Science Procedia 4:40-49.

Gao J B, Wang H (2019) Temporal analysis on quantitative attribution of karst soil erosion: A case study of a peak-cluster depression basin in Southwest China. CATENA 172:369-377.

Gao Y L, Li H B (2021) Influence of landscape pattern change on soil erosion in Han River Basin. Acta Ecologica Sinica 41:2248-2260. (in Chinese)

Gillies R R, Kustas W P, Humes K S (1997) A verification of the" triangle" method for obtaining surface soil water content and energy fluxes from remote measurements of the normalized difference vegetation index (NDVI) and surface. International Journal of Remote Sensing 18 (15) :3145-3166.

Han Z, Wang X Y, Song D D Li X X, Huang P, Ma M H (2019) Response of soil erosion and sediment sorting to the transport mechanism on a steep rocky slope. Earth Surface Processes and Landforms 44(12):2467-2478.

Higgitt DL (1991) Soil erosion and soil problems. Prog. Phys 15(1):91-100.

Jiang Z C, Lian Y Q, Qin X Q. Rocky desertification in Southwest China: Impacts, causes, and restoration. Earth-Science Reviews,2014, 132:1-12.

Kefi M, Yoshino K, Setiawan Y, Khemaies Z (2011) Assessment of the effects of vegetation on soil erosion risk by water: a case of study of the Batta watershed in Tunisia. Environmental Earth Sciences 64(3):707-719.

Laboratory U (1995) USDA-Water Erosion Prediction Project: hillslope profile and watershed model documentation. NSERL Report.

Lal R (2003) Soil erosion and the global carbon budget. Environment International 29(4):437-450.

Li R, Chen K, Liu Y L, Gu Z K Wen Y Q, Li Q G, Liu F X (2019) Characteristics of runoff and sediment in karst area of northern Guizhou province based on small watershed scale. Transactions of the Chinese Society of 
Agricultural Engineering 35(11):139-147. (in Chinese)

Li R, Pan L D (2021) Research status of the relationship between rock exposure and soil and water loss and discussion on the existing problems in the research of rocky desertification factors 35(5):10-15+23. (in Chinese)

Li R, Wu Q L, Zhang J J, Wen Y Q, Li Q G (2019) Effects of land use change of sloping farmland on characteristic of soil erosion resistance in typical karst mountainous areas of Southwestern China. Polish Journal of Environmental Studies 28(4): 2707-2716.

Liu B Y, Nearing M A, Risse L M (2000) Slope Length Effects on Soil Loss for Steep Slopes. Soil Science Society of America Journal 64(5): 1759-1763.

Liu B Y, Zhang K L, XieY (2002) An empirical soil loss equation//Proceedings 12th International Soil Conservation Organization Conference, Vol.Il: Process of Soil Erosion and Its Environment Effect. Beijing: Tsinghua University Press 21-25.

Ma Q H, Zhang K L (2018) Progresses and prospects of the research on soil erosion in karst area of southwest China. Progress in Geography 33(11): 1130-1141. (in Chinese)

L Martínez-Zavala, A Jordán (2008) Effect of rock fragment cover on interrill soil erosion from bare soils in Western Andalusia, Spain. Soil Use and Management 24(1):108-117.

McCool D K, Brown L C, Foster G R, Mutchler C K, Meyer L D (1987) Revised slope steepness factor for the Universal Soil Loss Equation. Transactions of the ASAE-American Society of Agricultural Engineers (USA) 30(5):1387-1396.

Ni J P, Yuan D X, Xie D L, Wei C F (2010) Estimating soil erosion in small watershed of karst valley area using GIS. Journal of Basic Science and Engineering 18(2):217-225. (in Chinese)

Oldeman L R (1994) Global Extent of Soil Degradation. Recovering Political Philosophy.

Renard K G, Ferreira V A (1993) RUSLE model description and database sensitivity. Journal of Environmental Quality 22(3): 458-466.

Sharpley A N, Williams J R (1990) EPIC-erosion/productivity impact calculator: 1. Model determination. US Department of Agriculture.

Shi Z H, Ai L, Li X, Huang X D, Wu G L, Liao W (2013) Partial least-squares regression for linking land-cover patterns to soil erosion and sediment yield in watersheds. Journal of Hydrology 498:165-176.

Shi Z H, Guo G X, Zeng Z J, Chen J C, Wang T W, Cai C F (2006) Study on rainfall erosivity of the characteristics and daily rainfall erosivity model in Wuhan city. Soil and Water Conservation in China (1):2224. (in Chinese) 
Tarolli P, Sofia G (2016) Human topographic signatures and derived geomorphic processes across landscapes. Geomorphology 255(4), 140-161.

Wang K, Wang H J, Shi X Z, Weindorf D C, Yu D S, Liang Y, Shi D M (2009) Landscape analysis of dynamic soil erosion in Subtropical China: A case study in Xingguo County, Jiangxi Province. Soil and Tillage Research 105(2):313-321.

Wang W, Zhang S, Ying L, Deng R Yan Y (2009) Research on the relationship between soil erosion and landscape pattern in the Wuyuer River basin based on GIS. Proceedings of SPIE-The International Society for Optical Engineering 7491:749107-749107-8.

Wang J P, Yang L, Wei W, Chen L T, Huang Z L (2011) Effects of landscape pattern on watershed soil erosion and sediment delivery in hilly and gully region of the Loess Plateau of China: patch class level. Acta Ecologica Sinica 31(19):5739-5748. (in Chinese)

Wang X Y, Li Z L, Cai C F, Shi Z H, Xu Q X, Fu Z Y, Guo Z L (2012) Hydrological response of sloping farmlands with different rock fragment covers in the purple soil area of China. Journal of Hydrologic Engineering 18(4):446-456.

Wei O, Skidmore A K, Hao F, Wang T (2010) Soil erosion dynamics response to landscape pattern. Science of the Total Environment 408(6):1358-1366.

Wei X P, Xie S Y, Zhang Z W, Chen Z X (2011) Characteristics of surface soil erosion of karst vally in different land use types at Nanping in Chongqing. Transactions of the Chinese Society of Agricultural Engineering 27(6):42-46. (in Chinese)

Wischmeier W H, Smith D D (1978) Predicting Rainfall Erosion Losses-A Guide to Conservation Planning. United States: Department of Agriculture. Agriculture handbook (USA).

Xie T T (2016) Assessment of Soil Erosion in Karst Area Based on RUSLE Model-A Case Study in the Southwest of Songzi. Huazhong University of Science and Technology. (in Chinese)

Xiong M, Sun R, Chen L (2019) A global comparison of soil erosion associated with land use and climate type. Geoderma 343:31-39.

Xiong K N, Li J, Long M Z (2012) Features of soil and water loss and key issues in demonstration areas for combating karst rocky desertification. Acta Geographica Sinica 67(7):878-888. (in Chinese)

Yang K J, Lu C H (2018) Evaluation of Land-Use Change Effects on Runoff and Soil Erosion of a Hilly Basin the Yanhe River in the Chinese Loess Plateau. Land Degradation \& Development 29(4):1211-1221.

Zhang H M, Yang Q K, Li R, Liu Q R, Moore D, He P, Ritsema C J, Geissen V (2013) Extension of a GIS procedure for calculating the RUSLE equation LS factor. Computers \& Geosciences 52, 177-188.

Zhang S, Xiong D H, Wu H, Yuan Y, Li W X, Zhang W D (2021) Research on Spatial Variation of Soil Erosion in Sunshui River Basin Based on RUSLE Model. Journal of Soil and Water Conservation 35:24-30. (in Chinese) 
Figures

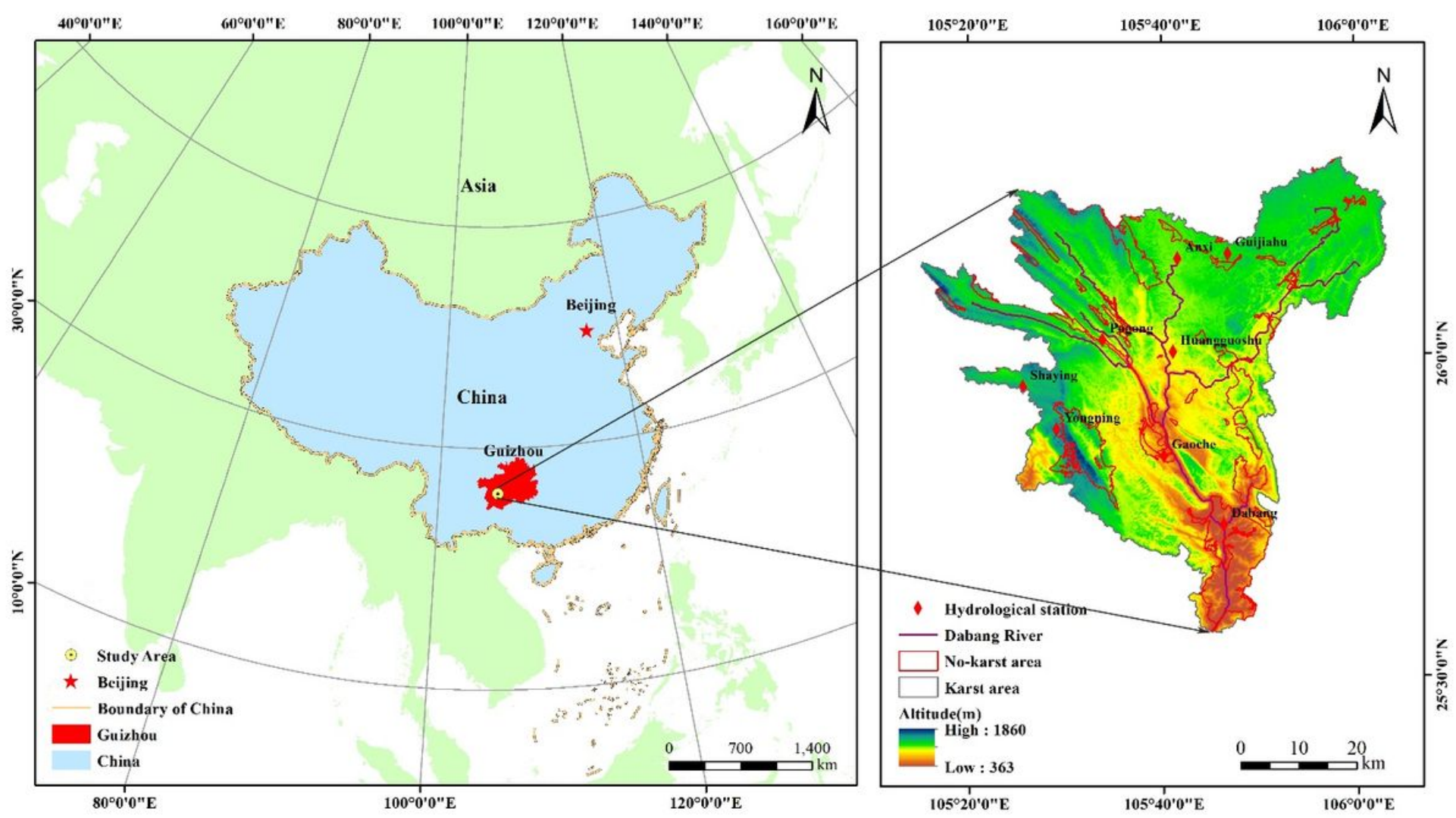

Figure 1

The location of the study area in Guizhou Province, China and the regional topography 

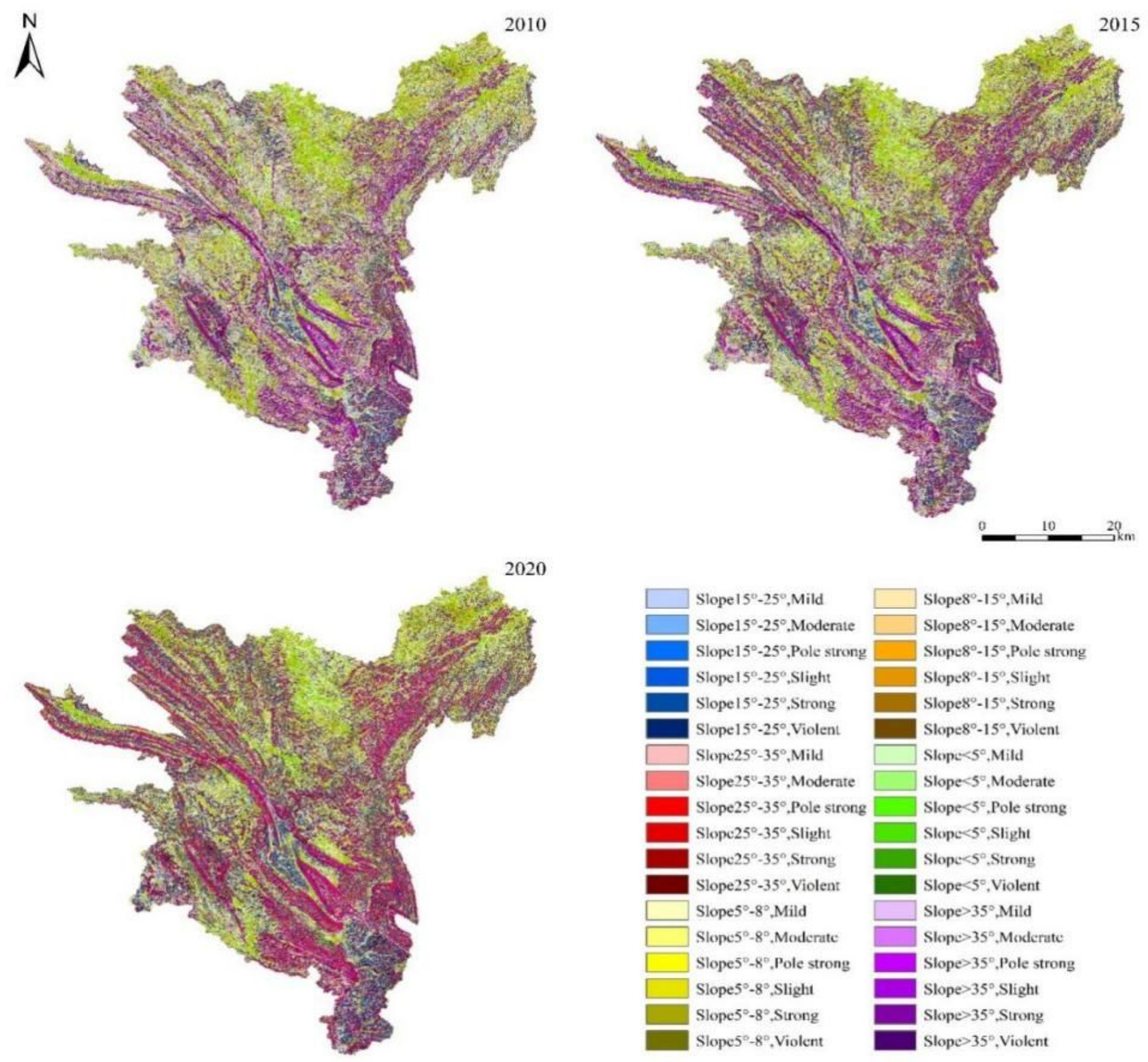

\begin{tabular}{|c|c|}
\hline Slope $15^{\circ}-25^{\circ}$, Mild & Slope $8^{\circ}-15^{\circ}$, Mild \\
\hline Slope $15^{\circ}-25^{\circ}$,Moderate & Slope $8^{\circ}-15^{\circ}$, Moderate \\
\hline Slope $15^{\circ}-25^{\circ}$, Pole strong & Slope $8^{\circ}-15^{\circ}$,Pole strong \\
\hline Slope $15^{\circ}-25^{\circ}$, Slight & Slope $8^{\circ}-15^{\circ}$, Slight \\
\hline Slope $15^{\circ}-25^{\circ}$, Strong & Slope8 $8^{\circ}-15^{\circ}$, Strong \\
\hline Slope $15^{\circ}-25^{\circ}$. Violent & Slope $8^{\circ}-15^{\circ}$, Violent \\
\hline Slope $25^{\circ}-35^{\circ}$, Mild & Slope $<5^{\circ}$, Mild \\
\hline Slope $25^{\circ}-35^{\circ}$, Moderate & Slope $<5^{\circ}$, Moderate \\
\hline Slope $25^{\circ}-35^{\circ}$, Pole strong & Slope $<5^{\circ}$, Pole strong \\
\hline Slope $25^{\circ}-35^{\circ}$,Slight & Slope $<5^{\circ}$, Slight \\
\hline Slope $25^{\circ}-35^{\circ}$, Strong & Slope $<5^{\circ}$, Strong \\
\hline Slope $25^{\circ}-35^{\circ}$. Violent & Slope $<5^{\circ}$, Violent \\
\hline Slope $5^{\circ}-8^{\circ}$, Mild & Slope $>35^{\circ}$, Mild \\
\hline Slope $5^{\circ}-8^{\circ}$. Moderate & Slope $>35^{\circ}$, Moderate \\
\hline Slope $5^{\circ}-8^{\circ}$. Pole strong & Slope $>35^{\circ}$, Pole strong \\
\hline Slope $5^{\circ}-8^{\circ}$,Slight & Slope $>35^{\circ}$, Slight \\
\hline Slope $5^{\circ}-8^{\circ}$,Strong & Slope $>35^{\circ}$, Strong \\
\hline Slope $5^{\circ}-8^{\circ}$, Violent & Slope $>35^{\circ}$, Violent \\
\hline
\end{tabular}

Figure 2

Soil erosion under different slopes 

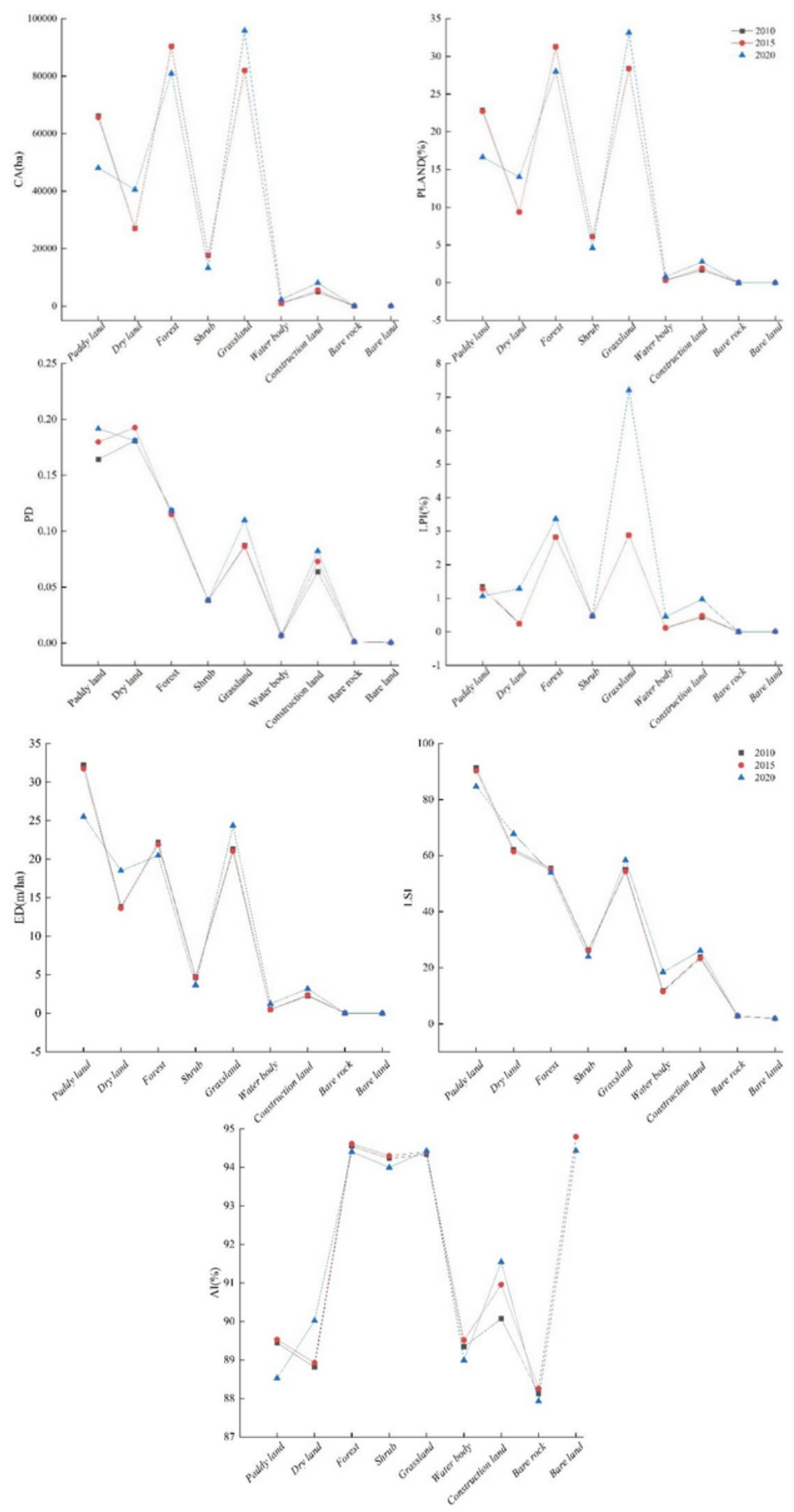

Figure 3

Type level index of Dabang River from 2010 to 2020 


\begin{tabular}{|c|c|c|c|c|c|c|c|}
\hline CA & & & & & & & \\
\hline 1.00 & PLAND & & & & & & \\
\hline 0.62 & 0.62 & PD & & & & & \\
\hline 0.84 & 0.84 & 0.36 & LPI & & & & \\
\hline 0.90 & 0.90 & 0.83 & 0.64 & ED & & & \\
\hline 0.77 & 0.77 & 0.94 & 0.48 & 0.95 & LSI & & \\
\hline 0.45 & 0.45 & -0.10 & 0.51 & 0.15 & 0.00 & $\mathrm{Al}$ & \\
\hline 0.67 & 0.67 & 0.17 & 0.65 & 0.40 & 0.27 & 0.85 & A \\
\hline
\end{tabular}

Figure 4

Correlation Analysis between patch type index and soil erosion 